\title{
Reduction of Vinyl Chloride Monomer Concentration in Poly Vinyl Chloride
}

\author{
Shukla Harsh $\mathbf{B}^{1}$, Shukla Akanksha $\mathbf{H}^{2}$ \\ ${ }^{1}$ Lecturer, Chemical Engineering Department, Shri K.J. Polytechnic, Bharuch
}

\begin{abstract}
The polymerization reaction in the reactor takes place by means of chain-growth polymerization of Vinyl Chloride Monomer (VCM). To make the Polyvinyl Chloride (PVC) as per the requirements of the consumer market, many other additives are added into it. This paper is based on suspension polymerization method for PVC production. The monomer recovery section recovers residual amount of the VCM from final PVC slurry. The final PVC slurry is sent to filtration, drying and bagging \& packing section. The excess amount of VCM in it will cause some severe problems. Excess VCM amount causes severe effects on environment, product economy as well as on process part. Focus of this paper is on finding out all possible sources which are causing this problem of excess VCM into the final PVC slurry.
\end{abstract}

Keywords: RVCM, VCM, PVC, Suspension polymerization, monomer recovery process

\section{Introduction ${ }^{[1]}$}

$80 \%$ of total Poly Vinyl Chloride is made from Vinyl Chloride Monomer using Suspension Polymerization method in world. It is a semi batch processes and uses a Continuous Stirred Tank Reactor. PVC in general is used for construction of storage tanks, building items, pipes, sheets, specific moulded objects, containers, tubes, pipes, sheets, films, etc.

The polymerization reaction in the reactor takes place by means of chain-growth polymerization of Vinyl Chloride Monomer (VCM). To make the Polyvinyl Chloride (PVC) as per the requirements of the consumer market, many other additives are added into it.

The main problem is the amount of R-VCM in the final PVC slurry, which has to be less than 1 ppm amount but it is present in it about 5 ppm.

The final PVC slurry is sent to filtration, drying and bagging \& packing section. The excess amount of VCM in it will cause some severe problems so it has to be lower down anyhow.

\section{Normal Recovery Method ${ }^{[1,2]}$}

Under normal conditions a small amount of recovery of VCM takes place in the polymerizer. Normally, unrecovered slurry is pumped to the flash tank where most of the VCM is recovered. The remainder is removed in the stripping column. When the polymerization is ended by the injection of shortstop into the polymerizer there is a significant quantity of unreacted VCM which must be recovered to be used again in subsequent charges.

The normal method of recovery is by partial degassing in the flash tank followed by continuous steam stripping in the slurry stripping column. As a standby, system equipment is provided to allow recovery and batch steam stripping in the polymerizers.
Problem and Effects ${ }^{[1,3]}$ :

Excess Amount of VCM (residual) In Final PVC Slurry creates a problem which affects environment, process economy and product economy.

\section{Affecting the Environment}

The VCM is having main content of chlorine into it. It is the main reason that VCM as a compound is the "carcinogen of class- $A$ " which endangers the environment in a very stunned manner.

So the excess amount of VCM in final PVC slurry makes it environmentally problematic and also unacceptable which will affect the process plant as a whole. The excess amount has to be lower down to the set one or desired one due to these sorts of reasons.

The exposure of VCM to the environment will affect the ecosystem as a whole which will cause some real severe problems. The effects may lead to some dangerous results.

\section{Affecting the Process Economy}

The final PVC slurry from the stripping column is sent to the DRYING section, into a rotary dryer. Due to the excess amount of VCM, as it incorporates much over the chlorinethe main constituent, the blades of the rotary dryer will get corroded. For the sake of brevity into the process, almost in every few months the blades have to be changed due to corrosion.

This entire "corrosion of blades of rotary drier" affects the process economy in a very severe mode as the cost of all replacement part will be much more and will get the disturbances into smoothness of the process.

\section{Affecting the Product Economy}

The PVC in the final product form is the PVC white powder. This is sold to the consumers as a product with basic variation in recipe as per the requirements of the different grades of it. Excess amount of VCM affects the product economy. 


\section{International Journal of Science and Research (IJSR) \\ ISSN (Online): 2319-7064 \\ Index Copernicus Value (2013): 6.14 | Impact Factor (2015): 6.391}

The VCM contamination affects the products by "creating the surface deflects called ,fished-eyes ${ }^{\text {ee }}$ in PVC films and other PVC products" where appearance is critical. This makes the looks of product moulds very badly which gets the reduction in pricing of PVC resins.

Also this phenomenon can lead to "the failure into the sites of electrical insulation" and also affects the other product appliances. Ultimately it affects the product economy on a much larger scale. The origin of this problem falls into two categories:

(I) Polymerization Process ${ }^{[2,4,5,6]}$ :

(a) The Diffusion Mechanism of Vinyl Chloride Monomer (VCM) Particles into Polymeric Chain of Polyvinyl Chloride (PVC).

When the polymerization process is taking place, the monomers are binding with each other to form a one long polymeric chain, and at this moment the diffusion mechanism of any monomer is very crucial. The VCM particles will get diffused into the chain with some sort of specific mechanism. Now the mechanism will be greatly affected by the process parameter and one must take a look around that.

(b) The Particle Size Distribution Problem of Vinyl Chloride Monomer (VCM)

The control of the average particle size and size distribution in the suspension polymerization of vinyl chloride monomer is an important parameter to determine, not only the latex characteristics, but also the properties of the final dispersion powder in several industrial applications. The operating variables like temperature, water to monomer weight ratio, concentrations of initiator, emulsifier, and agitation speed are the ones which influence the particle distribution at the most.

(c) The Poor Recycle Quality of Residual Vinyl Chloride Monomer (R-VCM)

The quality of the recycle stream must equal to that of the virgin VCM to ensure process control. Solids from the condenser, from storage, or from the recycle VCM piping system must be recovered prior to the PVC reactor to ensure PVC product quality. It may be possible that the recovered monomer stream and virgin monomer stream are not matching which may change the entire process avenue into the reactor.

(d) The Improper polymerization process taking place into the reactor:

The reactor is the key equipment where the main polymerization process is taking place. Now any problem in that will affect the entire process and this will create some severe damage to the product. 100 percent conversion of monomer is not feasible and the amount of un-reacted monomer will be accumulated in some amount.
(II) Monomer recovery Process ${ }^{[1,6]}$ :

(a) The Inappropriate Operating Condition Hold in Flash Tank

The flash tank is the first place where recovery of un-reacted monomer will be done. Either reactor or the process parameters will influence the performance of flash tank. As it is operated under the vacuum, the deviation in these parameters will cause the problem.

\section{(b) The Contamination Problem in Monomer Recovery Section}

In the transportation of recovered monomer from the stripping as well as flash tank, it might be possible that the vapors will get condensed in the piping section before reaching into condenser and get accumulated. It might get diffused into new R-VCM stream from columns and that will change the recipe in reactor which may cause the issue of excess VCM in either manner.

\section{(c) The inefficient workability of stripping column.}

The stripping column is an important factor because the problem is directly related just after it. It might be possible that the separation in the column by means of continuous steaming is not getting in a proper manner. Due to that the VCM in unreacted amount will remain as it is in PVC slurry or as another option we may also say that the stripping column is forced to perform recovery operation way over its capacity.

\section{Result and Discussion ${ }^{[4,5,6,7,8]}$ :}

By applying the knowledge and scientific data brought from different useful research papers and guidance of some real acknowledged fraternity, the final pathway to sort out this excess amount of VCM problem by means of a journey leading to a destination of four elucidations:

Elucidation I: The production of non-porous PVC resins: The PVC resins producing into the reactor is having porous nature and the glassy polymers will always have the diffusion of their respective monomers into them as they will be natured by it. The pores must be lessening then to terminate this diffusion procedure and the stripping will be in effect then.

Elucidation II: The rapid desorption rate of VCM particles from PVC resin: As the diffusion of VCM is taking place into PVC resins, the swelling due to plasticization entraps the VCM molecules and it will not allow them to desorb. As a matter of fact, no stripping operation will be useful here, so the diffusion mechanism and the rates of in-diffusion as well as rapid out-diffusion have to be designed for VCM particles. This will be exploited to get the maximum desorption rate as more and more residual monomer will be removed.

Elucidation III: The proper use of suitable surfactants: Fluids are having so many properties which will make sure to be manipulated in such a way that we can get some good outcome. The one property is surface tension. Suitable surfactants can be used. The working scheme is very simple. The surfactant will be chosen on the proper selection and they will set on the VCM molecules. In that way molecule 


\section{International Journal of Science and Research (IJSR) \\ ISSN (Online): 2319-7064}

Index Copernicus Value (2013): 6.14 | Impact Factor (2015): 6.391

size will be increased and no diffusion will take place or one more thing can be happened is the deposition of surfactants on pores which will again stop VCM molecules ${ }^{e e}$ diffusion procedures.

Elucidation IV: The use of microwave heat radiation on the powder of PVC: The rapid removal of residual VCM from PVC resin is achieved without deleterious decomposition or other impairment of resin properties, by subjecting the polymer in presence of water to microwave irradiation. The method is applicable to PVC homo-polymers, but also to copolymers thereof containing a major proportion of polymerized VCM. Removal of over 99\% VCM is obtained in treating periods of general 6-8 minutes. In many instances the monomer content is reduced to non-detectable quantities.
[8] https://www.researchgate.net/publication/239675113_Eff ect_of_the_Phase_Ratio_on_the_Particle_Properties_of_ Polyvinyl_chloride_Resins_Produced_by_Suspension_P olymerization

[9] Aleck H. Alexopoulosb, Costas Kiparissides, "On the prediction of internal particle morphology in suspension polymerization of vinyl chloride. Part I: The effect of primary particle size distribution" Chemical Engineering Science(2007), Volume 62, Issue 15, August 2007, p.p. 3970-3983

\section{Conclusion}

The main problem is "excess amount of VCM". Rather than sticking to the concept of the removal of VCM from PVC we have provided various other alternatives also. Decreasing the porosity of the polymer will prevent the diffusion of VCM into PVC which will reduce the contamination. Also by controlling the diffusion mechanism we will be able to adjust the rate of diffusion. The VCM particles will tend to stay in the reaction slurry rather than entering the porous PVC particles. The microwave irradiation technique is one of the most important as well as modern methods or the removal of VCM from PVC slurry. Surfactants are used to decrease the surface tension of the unreacted molecules or product molecules. These surfactants are highly specific in nature. That either, increases the size of the unreacted VCM molecules or decrease the size of pores present on PVC molecule which will hault the diffusion process. The processes mentioned are working and tested under specific conditions. These can be applied at an industrial level. The discretion and combinations of process depend upon the R\&D of the industry.

\section{References}

[1] http://indiansleague.yolasite.com/resources/Encyclopedia \%20of\%20Chemical\%20Technologywhite\%20paper.pdf

[2] Mahdi Pourmehr, Amir H. Navarchian, "Batch Emulsion Polymerization of Vinyl Chloride: Application of Experimental Design to Investigate the Effects of Operating Variables on Particle Size and Particle Size Distribution" Journal of Applied Polymer Science (2009), 111(1), p.p.338 - 347

[3] http://www.ndt.net/article/aero2010/papers/we1a2.pdf

[4] N. Etesami, M. Nasr Esfahany, R. Bagheri,

[5] "Effect of the Phase Ratio on the Particle Properties of Poly(vinyl chloride) Resins Produced by Suspension Polymerization" 110, Issue 5, Journal of Applied Polymer Science, (2008) , p.p. 2748-2755

[6] D. Maggioris, A. Goulas, A. H. Alexopoulos, E. G. Chatzi, C. Kiparissides, "Prediction of particle size distribution in suspension polymerization reactors: effect of turbulence non homogeneity " Chemical Engineering Science, 55 (2000), p.p. 4611-4627

[7] J. H. P. Brooman, R. P. BritoBraskem, "PVC Stripping column modeling and simulation" 